\title{
Markers of muscle damage and strength performance in professional football (soccer) players during the competitive period
}

\author{
Vladimir Khaitin ${ }^{1,2}$, Eduard Bezuglov ${ }^{3,4,5}$, Artemii Lazarev ${ }^{3,5}$, Sergey Matveev ${ }^{1}$, Olga Ivanova ${ }^{6}$, \\ Nicola Maffulli ${ }^{7,8,9,10}$, Evgeny Achkasov ${ }^{3}$
}

${ }^{1}$ Pavlov First Saint-Petersburg State Medical University, Saint-Petersburg, Russia; ${ }^{2}$ FC Zenit, Saint-Petersburg, Russia; ${ }^{3}$ Sechenov First Moscow State Medical University (Sechenov University), Moscow, Russia; ${ }^{4}$ Federal Research and Clinical Center of Sports Medicine and Rehabilitation of Federal Medical Biological Agency, Moscow, Russia; ${ }^{5}$ High Performance Sport Laboratory, Moscow Witte University, Moscow, Russia; ${ }^{6}$ Lomonosov Moscow State University, Moscow, Russia; ${ }^{7}$ Department of Musculoskeletal Disorders, Faculty of Medicine and Surgery, University of Salerno, Salerno, Italy; ${ }^{8}$ Department of Medicine, Surgery and Dentistry, University of Salerno, Baronissi (SA), Italy; ${ }^{9}$ Centre for Sports and Exercise Medicine, Barts and The London School of Medicine and Dentistry, Mile End Hospital, Queen Mary University of London, London, England;

${ }^{10}$ School of Pharmacy and Bioengineering, Keele University School of Medicine, Stoke on Trent, England

Contributions: (I) Conception and design: V Khaitin, A Lazarev; (II) Administrative support: E Bezuglov, S Matveev, A Lazarev; (III) Provision of study materials or patients: E Bezuglov, A Lazarev, O Ivanova; (IV) Collection and assembly of data: E Achkasov, O Ivanova, S Matveev; (V) Data analysis and interpretation: A Lazarev, N Maffulli, E Achkasov; (VI) Manuscript writing: All authors; (VII) Final approval of manuscript: All authors. Correspondence to: Nicola Maffulli. Department of Musculoskeletal Disorders, Faculty of Medicine and Surgery, University of Salerno, Salerno, Italy; Department of Medicine, Surgery and Dentistry, University of Salerno, Baronissi (SA), Italy; Centre for Sports and Exercise Medicine, Barts and The London School of Medicine and Dentistry, Mile End Hospital, Queen Mary University of London, London, England; School of Pharmacy and Bioengineering, Keele University School of Medicine, Stoke on Trent, England. Email: n.maffulli@qmul.ac.uk.

Background: The present study investigated the impact of competitive soccer on the short-term changes in isometric strength of the adductor muscle group during the competitive season.

Methods: In this cohort study we evaluated the association between a serum marker of muscle damage [creatine phosphokinase (CPK)] and isometric strength of the adductor muscles of the hip in 30 professional football players (age: $26.7 \pm 2.9$ years) during two seasons of the national top-level championship. Serum CPK level was determined the day before the match, 12-20, 36-48, 60-72 h after the match. The maximum voluntary isometric contraction force of the adductor muscles complex was determined immediately after having taken blood samples.

Results: There was evidence of a statistically significant positive association between age, body mass index (BMI), percentage of body fat, and muscle strength, and between weight and muscle strength. There was evidence of a statistically significant negative association between the level of CPK and the maximum isometric strength of the adductors of soccer players. Changes in CPK levels were associated with the muscle strength recovery trend $(\mathrm{P}<0.001)$. The strength/CPK ratio at different time points had a $\mathrm{U}$-shaped curve.

Conclusions: Exercise induced muscle damage significantly affects the strength of the adductor muscle group of professional soccer players during the competitive period. The lower the CPK level, the greater the athletes' strength at a given time point. Also, the greater the decrease in CPK level, the greater the rate of strength restoration.

Keywords: Creatine kinase; muscle strength; adductors; isometric contraction; football

Submitted May 27, 2020. Accepted for publication Oct 25, 2020.

doi: 10.21037/atm-20-2923

View this article at: http://dx.doi.org/10.21037/atm-20-2923 


\section{Introduction}

During a match, football players perform a multitude of movements, involving muscle contractions which eventually may cause muscle damage (1-3), with release of creatine phosphokinase $(\mathrm{CPK})$ and other markers of such damage [for example, myoglobin and lactic dehydrogenase (LDH)] in the bloodstream (4-7). Exercise-induced damage to sarcomeres, cytoskeleton and sarcolemma is accompanied by transient muscle strength loss, and leads to delayed onset muscle soreness (DOMS) (8).

The reliability of serum CPK levels as a marker of muscle damage is debated $(9,10)$. Some ethnic groups exhibit naturally increased levels of serum CPK following physical activity: this is not in any way pathological (6). Higher than normal levels of tissue CPK activity may increase the availability of cellular energy and improve myofibril contraction responses. Therefore, high levels of serum CPK, in the absence of muscle damage or other pathological conditions, may reflect the level of enzyme tissue activity. In such individuals, the serum CPK may be higher $(6,11)$.

Serum CPK level is a marker of muscle microtrauma after exercise (12-14), and has been assessed during the competitive season in professional soccer players $(15,16)$, using point-of-care testing $(1,15,16)$. In some studies, CPK was used as an indicator of muscle fatigue, and there is an evident association between the level of CPK and very highintensity running during the match $(17,18)$.

In professional football (soccer), sports medicine professionals need objective and easy-to-perform tests to assess changes in strength in relation to the effects of exercise induced muscle damage. One of these tests is the five-second squeeze test, which is a valid indicator of sportsrelated hip and groin function (19).

In professional soccer, lower limb strength training produces measurable performance benefits. However, from a performance development view point, specifically considering fatigue and injury prevention, the advantages of increased lower body strength have received limited attention at the elite level of the game (20).

Pain associated with adductors muscles is the most common clinical finding on palpation and isometric muscle contraction in professional athletes, and can be a serious problem affecting the functional state and physical performance of the players. Weakness of the adductor muscles is associated with this clinical manifestation (21-23).

Every second football player suffers from pain in the adductor muscles during one football season, and every third football player begins the competition season with discomfort in the area close to the attachment of the adductor muscles to the pelvis, while a third of the players have residual discomfort dating back from the previous competitive season (24-26).

The present study investigated the impact of competitive soccer on the short-term changes in isometric strength of the adductor muscle group during the competitive season.

We analysed the association of CPK level to a series of anthropometric variables, and evaluated how this marker of muscle damage is associated with changes in the ability of the hip adductor muscle group to produce isometric strength. We wished to test the null hypothesis that there was no association between serum level of CPK and changes in the isometric strength of the hip adductor muscle group.

The aim of the study was to develop a relatively simple method to monitor the functional state of football players, and potentially to find a method to check and evaluate the adaptation to exercise and recovery in professional football.

We present the study in accordance with the STROBE reporting checklist (available at http://dx.doi.org/10.21037/ atm-20-2923).

\section{Methods}

All the procedures described in the present study were approved by our Local Ethics Committee (Sechenov Moscow State Medical University; Protocol No. 11-19, special meeting on 25.07.2019), and all participants signed a written informed consent. The study was conducted in accordance with the Declaration of Helsinki (as revised in 2013).

All athletes participating in the present study satisfied the following requirements:

* Participation in pre-season training camp;

* CPK level determination immediately prior to the beginning of the competitive season;

* CPK level determination at each of the 3 time points after three games, each with a minimum of 75 -minute playing time;

* Identical physical loads in the training cycle (one training session every day 60-75 $\mathrm{min}$ );

* No adductor muscle injury 3 months prior to the first measurement.

\section{Clinical and laboratory monitoring}

In this cohort study, during two continuous seasons of 
the Premier League Championship (2017-2018 and 2018-2019), 30 professional male soccer players, all from the same professional team, were recruited (mean age: $26.7 \pm 2.9$ years; height: $181.0 \pm 5.5 \mathrm{~cm}$, body mass: $75.7 \pm 8.1$ $\mathrm{kg}$; percentage body fat: $10.1 \% \pm 1.3 \%)$. No player was lost to follow-up. All the players were white Caucasians, and were members of their national soccer teams, played in the Russian Premier League, UEFA Europa League and Champions League. A finger-prick fasting blood sample allowed to analyse $32 \mu \mathrm{L}$ of capillary blood to measure CPK concentration at five different time points: (I) before starting pre-season training after 2 or 3 weeks of rest; (II) $24 \mathrm{~h}$ before the match; (III) 12-20 h; (IV) 36-48 h; (V) 60-72 $\mathrm{h}$ after playing three matches during the competitive season (July-December, March-June in seasons of 2017/18, 2018/19). A total of 390 samples were taken. The Roche test-strips and the Roche Reflotron ${ }^{\circledR}$ Plus clinical chemistry system (Roche Diagnostics, F. Hoffmann-La Rosche, Basel, Switzerland) were used $(15,27)$. The middle finger of the non-dominant hand of each player was wiped with an antiseptic solution and punctured with an automatic lancet. Blood was aspirated into the heparinized glass tube with an automatic pipette (preset volume $32 \mu \mathrm{L}$ ), and immediately pipetted onto the test strip. The measurement is based on the principle of reflectance photometry. The Reflotron ${ }^{\circledR}$ Quality Control (QC) Kit should be used with the Reflotron ${ }^{\circledR}$ test strips to ensure that the strips were working correctly and gave accurate and reliable results. The Roche Reflotron ${ }^{\circledR}$ Precinorm U QC kit was used for calibration procedures, which were performed: with each new lot of test strips; with each new shipment of test strip; whenever there was any concern that the test result may be wrong (test strip not stored correctly; when there was concern that a user may not have performed the test correctly); and every 30 days regardless of any other calibration procedures.

\section{Strength testing}

After the fingertip blood sample had been taken, the maximal voluntary isometric strength of the hip adductor muscle group was assessed. With the players lying supine, with their hands along the body, each player was asked to produce a 5 seconds maximal isometric contraction in three different positions, namely at $0^{\circ}, 45^{\circ}$ and $90^{\circ}$ of hip flexion with 3 minutes rest between each maximal contraction (Figure 1). The Smart Groin Trainer dynamometer (NeuroExcellence, Braga, Portugal) was used for the measurement (in $\mathrm{kg}$ ) (28). The dynamometer was placed between the medial femoral condyles, enabling contraction of the pectineus, gracilis, short and long hip adductor muscles, and eliminating the influence of other muscles. Each player performed three attempts at each position, and the average per each position was used for statistical analysis. Before the test, each player warmed up performing passive resistance contraction and passive manual stretching of the adductors.

\section{Anthropometric testing}

Body composition analysis was performed using the "InBody720" body composition analyser, which employs bioelectric impedance (InBody CO, Seoul, Korea) (29,30). The analysis was performed the morning after a training session after an overnight fast.

\section{Measurement of physical activity during matches}

All the measurements of physical activity during matches were carried out using the InStat ${ }^{\circledR}$ kinematic system (Moscow, Russia) (31).

\section{Statistical analysis}

Data were entered into Excel tables using a tablet computer. Statistical analysis was performed using IBM SPSS Statistics software, version 23.0. The Wilcoxon signed-rank test was used to compare independent samples. Spearman's rank correlation coefficient has been used for correlation analysis. $\mathrm{P}<0.05$ was considered statistically significant. Individual coefficients of changes in serum levels were calculated: CPK_PRE was divided by CPK_BAS, CPK_ POST1 by CPK_PRE, CPK_POST2 by CPK_POST1, CPK_POST by CPK_POST2. This allowed to normalise for the individual variability in serum CPK levels, and calculate their increase rate.

\section{Results}

The results of the measurements at all time points $(24 \mathrm{~h}$ before the match, and $12-20,36-48$, and $60-72 \mathrm{~h}$ after the match) in three matches during the first $1 / 3$, second $1 / 3$ and third $1 / 3$ of the competitive season were compared using the Wilcoxon signed-rank test. No significant difference was detected $(\mathrm{P}=0.39)$, and therefore measurements from the first match were used for further analysis for all athletes.

The mean and standard deviation (SD) pre-match 

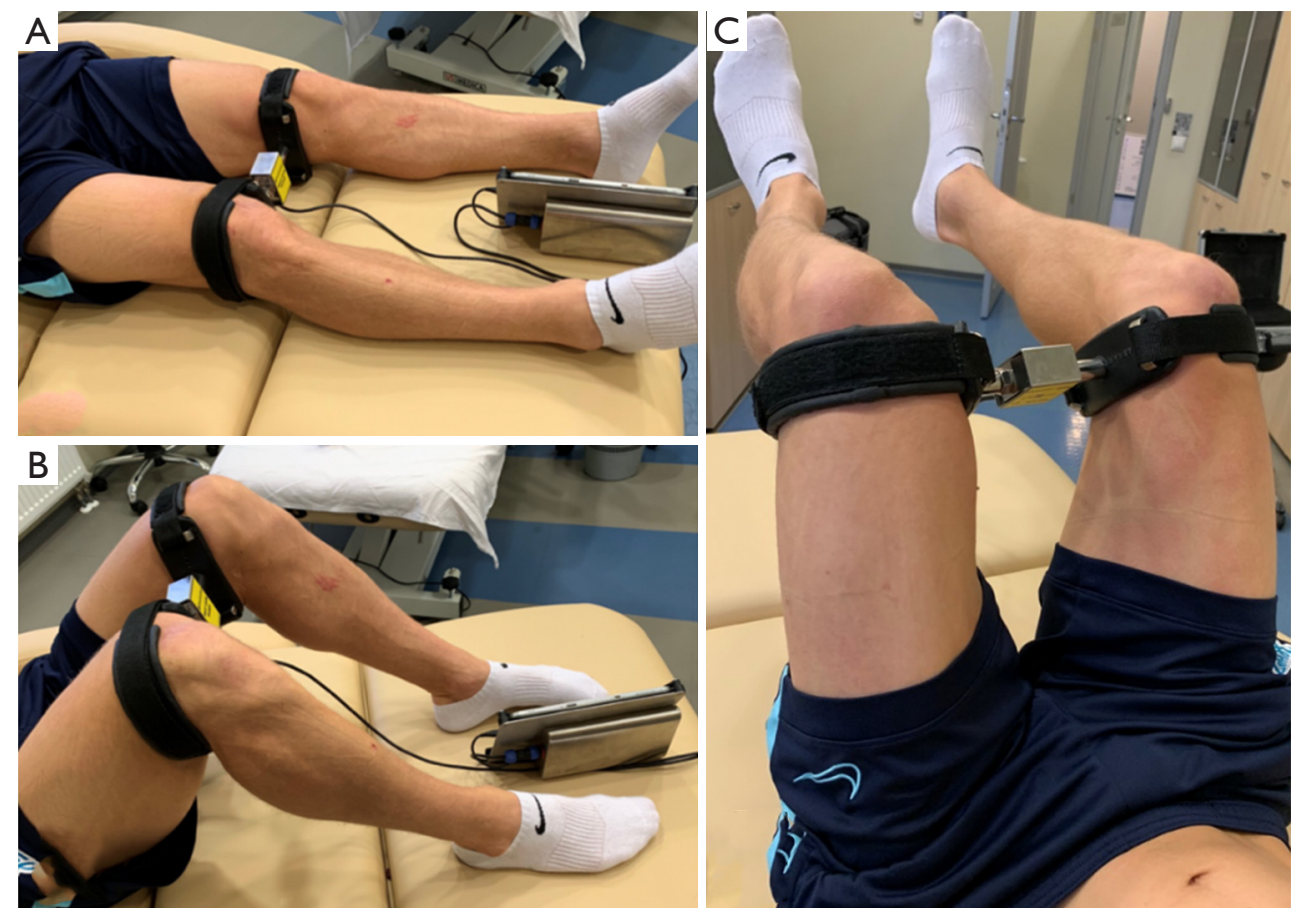

Figure 1 The adductor squeeze test at $0^{\circ}(\mathrm{A}), 45^{\circ}(\mathrm{B})$ and $90^{\circ}(\mathrm{C})$ of hip flexion.

strength values were: $0^{\circ}, 53.2 \pm 7.4 \mathrm{~kg} ; 45^{\circ}, 38.9 \pm 7.5 \mathrm{~kg} ; 90^{\circ}$, $45.7 \pm 7.3 \mathrm{~kg}$.

Measurements of physical activity during each match were carried out in each player. No statistically significant differences in the level of physical activity were found. The average value of the team total distance at the speed of more than $19.8 \mathrm{~km} / \mathrm{h}$ during all matches was $8,111 \pm 315 \mathrm{~m}$, with the average number of high-intensity activities at the speed of more than $19.8 \mathrm{~km} / \mathrm{h}$ during all matches being $615.5 \pm 49.0$.

There was no evidence of a statistically significant association between the age of the players, body mass index (BMI), body fat percentage and maximal isometric strength of hip adductor muscle group in the three different hip flexion positions. There was evidence of a statistically significant positive association between the height and the body mass of the players and the maximal isometric strength of the hip adductor muscle group in each of the flexion position in all measurements (Table 1).

There was no evidence of a statistically significant association between serum CPK levels and BMI, percentage of body fat, and body mass. There was evidence of a statistically significant positive association between baseline CPK concentration, 24 and 48 h post-game CPK levels and players' age (Figure 2, Table 2). Interestingly, the serum
$\mathrm{CPK}$ level at $72 \mathrm{~h}$ was associated with height.

The association between serum CPK level and maximal isometric strength of the hip adductor muscle group in three different hip flexion positions was studied. Serum CPK levels varied significantly in different players, and increased with the age of the athlete, as shown above, and also varied inter-individually. There was evidence of a statistically significant negative association between serum CPK levels and maximal isometric strength of the hip adductor muscle group at $0^{\circ}(\mathrm{P}<0.001 ; \mathrm{r}=-0.418), 45^{\circ}(\mathrm{P}=0.06 ; \mathrm{r}=-0.202)$ and $90^{\circ}$ flexion positions $(\mathrm{P}=0.001 ; \mathrm{r}=-0.363)$ (Figure 3 ).

Moreover, the changes in serum CPK level were associated with the rate of restoration of isometric strength: the lower the serum CPK level after the match, the higher the strength restoration rate (Figure 4).

There was a U-shaped CPK concentration/isometric strength ratio trend. A significant decrease was observed for the POST1 measurements $24 \mathrm{~h}$ after the match $(\mathrm{P}<0.001)$. $72 \mathrm{~h}$ after the match, the ratio has returned to basal values $(\mathrm{P}>0.05)$ (Figure 5).

\section{Discussion}

The present study evidenced a statistically significant negative association between serum CPK level and the 
Table 1 The relationship of age, height, weight, BMI, percentage of body fat with maximum isometric strength of the hip adductor muscle group (PRE: day before the match, POST1: 12-20 h after the match, POST2: 36-48 h, POST3: 60-72 h)

\begin{tabular}{|c|c|c|c|c|c|}
\hline Muscle strength $(\mathrm{kg})$ & Age (years) & Body mass (kg) & Height (cm) & Fat $\%$ & BMI $\left(\mathrm{kg} / \mathrm{m}^{2}\right)$ \\
\hline PRE_45 & $P=0.68$ & $\mathrm{R}=0.44, \mathrm{P}=0.01^{*}$ & $\mathrm{R}=0.42, \mathrm{P}=0.02^{*}$ & $P=0.13$ & $P=0.45$ \\
\hline PRE_90 & $P=0.21$ & $\mathrm{R}=0.52, \mathrm{P}=0.004^{*}$ & $\mathrm{R}=0.33, \mathrm{P}=0.07$ & $P=0.15$ & $P=0.31$ \\
\hline POST1_0 & $P=0.53$ & $R=0.32, P=0.08$ & $P=0.25$ & $R=-0.37, P=0.05^{\star}$ & $P=0.43$ \\
\hline POST1_90 & $P=0.40$ & $\mathrm{R}=0.48, \mathrm{P}=0.008^{*}$ & $\mathrm{R}=0.35, \mathrm{P}=0.06$ & $R=-0.33, P=0.07$ & $P=0.36$ \\
\hline POST2_0 & $P=0.55$ & $\mathrm{R}=0.37, \mathrm{P}=0.04^{*}$ & $P=0.17$ & $P=0.13$ & $P=0.33$ \\
\hline POST2_45 & $P=0.67$ & $\mathrm{R}=0.43, \mathrm{P}=0.02^{*}$ & $\mathrm{R}=0.43, \mathrm{P}=0.02^{*}$ & $R=-0.34, P=0.07$ & $P=0.43$ \\
\hline POST2_90 & $P=0.35$ & $\mathrm{R}=0.48, \mathrm{P}=0.007^{*}$ & $R=0.36, P=0.05^{\star}$ & $R=-0,33, P=0.08$ & $P=0.32$ \\
\hline POST3_90 & $P=0.26$ & $\mathrm{R}=0.48, \mathrm{P}=0.007$ & $\mathrm{R}=0.34, \mathrm{P}=0.06$ & $R=-0.31, P=0.09$ & $P=0.37$ \\
\hline
\end{tabular}

Statistically significant results are indicated with *. BMI, body mass index.

Table 2 Relationship of age, height, weight, BMI, percentage of body fat with serum CPK level (BAS-control measurement before pre-season training, PRE: on the day before the match, POST1: 12-20 h after the match, POST2: 36-48 h, POST3: 60-72 h)

\begin{tabular}{lccccc}
\hline CPK $(\mathrm{U} / \mathrm{L})$ & Age (years) & Height $(\mathrm{cm})$ & Body weight $(\mathrm{kg})$ & $\mathrm{BMI}\left(\mathrm{kg} / \mathrm{m}^{2}\right)$ & $\mathrm{Percentage}$ of body fat \\
\hline CPK_BAS & $\mathrm{R}=0.50, \mathrm{P}=0.006^{*}$ & $\mathrm{P}=0.12$ & $\mathrm{P}=0.90$ & $\mathrm{P}=0.70$ & $\mathrm{P}=0.21$ \\
CPK_PRE & $\mathrm{P}=0.52$ & $\mathrm{P}=0.89$ & $\mathrm{P}=0.50$ & $\mathrm{P}=0.29$ & $\mathrm{P}=0.50$ \\
CPK_POST1 & $\mathrm{R}=0.40, \mathrm{P}=0.03^{*}$ & $\mathrm{P}=0.25$ & $\mathrm{P}=0.24$ & $\mathrm{P}=0.65$ & $\mathrm{P}=0.24$ \\
CPK_POST2 & $\mathrm{R}=0.42, \mathrm{P}=0.02^{*}$ & $\mathrm{P}=0.64$ & $\mathrm{P}=0.17$ & $\mathrm{P}=0.25$ & $\mathrm{P}=0.89$ \\
CPK_POST3 & $\mathrm{P}=0.19$ & $\mathrm{R}=0.40, \mathrm{P}=0.03^{*}$ & $\mathrm{P}=0.42$ & & \\
\hline
\end{tabular}

Statistically significant results are indicated with *. BMI, body mass index; CPK, creatine phosphokinase.

maximal isometric strength of the hip adductor muscle group during the recovery period after a professional football match. In addition, the maximal isometric strength of the hip adductor muscle group in the professional football players under study showed evidence of a statistically significant association with body height and mass at all hip flexion positions. These findings carry valuable practical implications, as, considering these time dependent patterns of isometric strength changes, it will allow strength and conditioning coaches to better plan training during the competitive season.

A major strength of the present study is that this investigation was conducted on a cohort of elite professional male soccer players: this is a difficult task to accomplish during the competitive season of professional soccer. The results obtained are therefore a real reflection of the daily work in professional clubs.

We acknowledge that serum CPK levels alone may not accurately reflect the structural damage to muscle cells. Serum CPK levels can be affected by hydration status before eccentric exercise (9), hyperphosphatemia and hypermagnesemia (32), and may vary widely within subject groups of comparable male volunteers. Serum CPK levels may be also high from contraction-induced damage to the various muscles or following direct muscle injury.

Unfortunately, at present not all analytical methods and techniques are suitable for a quick, reliable and painless early diagnosis of muscle fatigue leading to muscle 

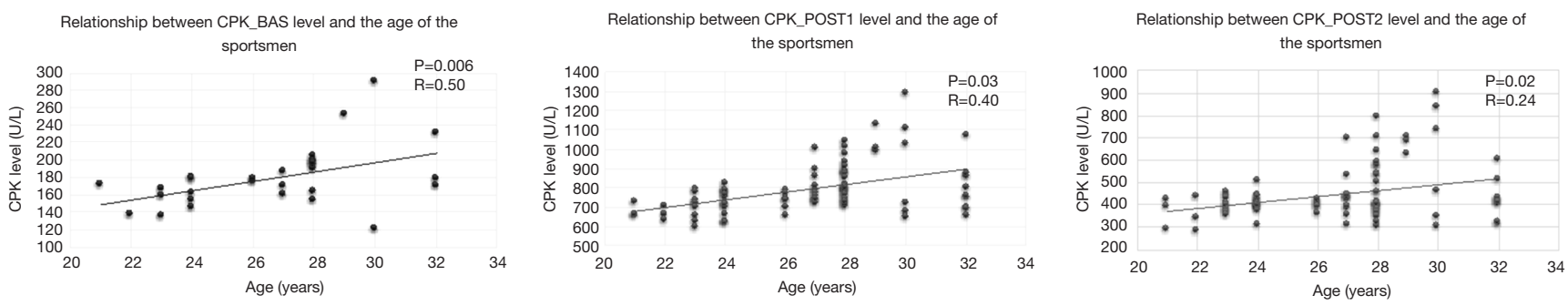

Figure 2 Relationship between the concentration of CPK and age of the soccer players. CPK, creatine phosphokinase.
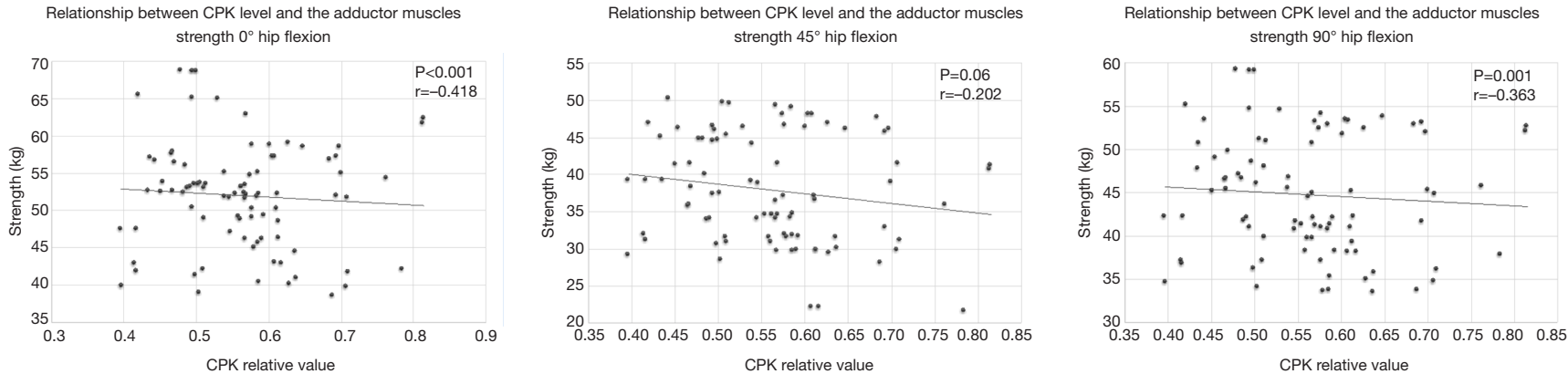

Figure 3 Relationship of the serum CPK level with the maximum isometric strength of the hip adductor muscle group $(\mathrm{kg})$ at $0^{\circ}$, $45^{\circ}$, and $90^{\circ}$ of hip flexion. CPK, creatine phosphokinase.
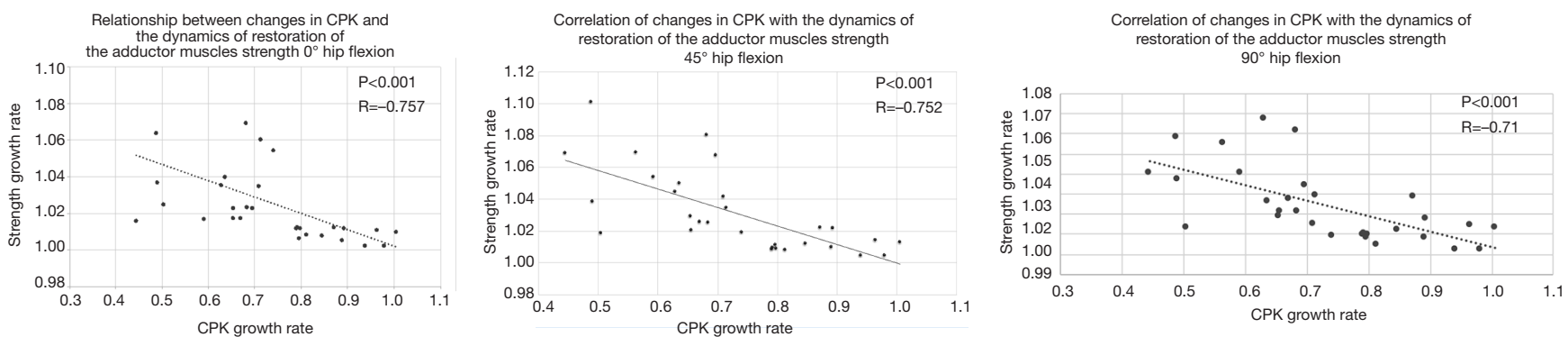

Figure 4 Relationship between changes in CPK and the kinetics of restoration of isometric strength of the adductor muscle strength at $0^{\circ}$, $45^{\circ}$, and $90^{\circ}$. CPK, creatine phosphokinase.
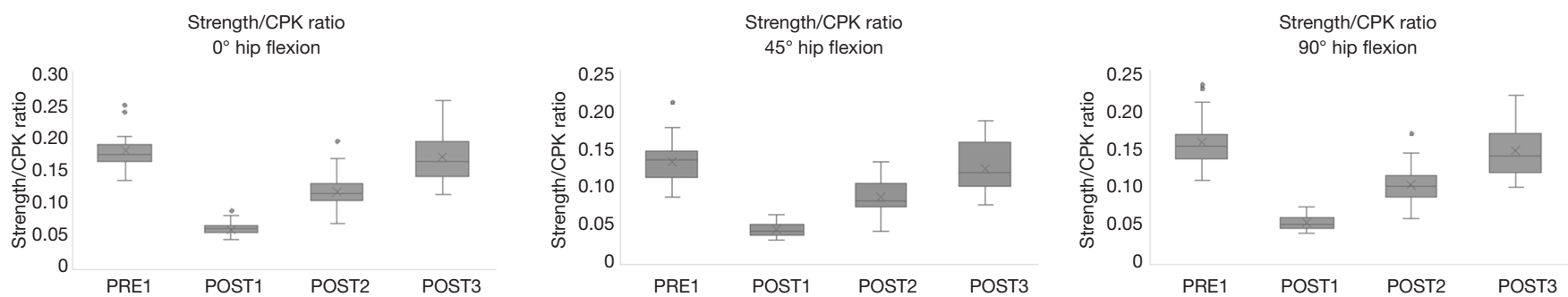

Figure 5 Strength/CPK ratio at different time points $0^{\circ}, 45^{\circ}$, and $90^{\circ}$. CPK, creatine phosphokinase. 
microdamage at the morphological level. In real life, such diagnosis should be easy to perform without stopping from the main activity.

Muscle biopsies have revealed similar ultrastructure damage to the $Z$ band of muscle fibres in the absence of differences in muscle soreness (33). In various studies, muscle biopsies have been performed to try and quantify muscle damage following exercise $(6,34)$. However, by definition they only give a snapshot of what is happening in the small portion of the muscle investigated. Therefore, muscle biopsies may not give the full picture of the damage to the muscle group(s) exercised, and the biopsy procedure may itself cause damage to muscle fibres (35). Muscle biopsy is nevertheless a direct method to examine muscle tissue, but it is invasive, and requires specialized equipment and expertise.

Other additional indirect indices of muscle damage such as magnetic resonance imaging studies and ultrasound assessment are useful, but can only identify existing structural damage (36).

There is a number of biochemical serum markers of inflammation and stress, such as lipid hydroperoxides, malondialdehyde, myoglobin, lactate, alpha-tocopherol, retinol, uric acid, which can assist in quantifying and substantiating muscle disturbance parameters (37). However, most of these indicators are too indirect and their changes are multifactorial.

The present study focussed on performing routine, affordable assessment of serum CPK level and strength of the hip adductor muscle group: these muscles are involved in soccer-specific repetitive movements, such as side running, kicking, crossing, and curling the ball (38). The injury rate of this anatomical region is $1.015-1.133$ injuries per 1,000 h playtime, and comprises $11-16 \%$ of all soccerrelated traumatic injuries (23).

Computer-assisted isokinetic dynamometry is widely used to assess hip muscle strength in athletes (39). This equipment is expensive, requires specialised training and experience, and, given its size and weight, cannot readily be used for pitch side purposes. Hand-held dynamometers are easy to use and inexpensive, but their reliability can be a problem (40). The disadvantages of isokinetic and handheld dynamometers led us to employ the device used in the present investigation, which has the advantage of portability, is not dependent on the strength of the examiner, and is easily placed in an anatomically reproducible location over the extremities to test (41).

We chose the isometric type of contraction during testing, because isometric strength testing exerts a lower load on the skeletal system in comparison to eccentric contractions, minimising pain and the risk of trauma (42). Thus, we believe that isometric testing is most beneficial for diagnostic and prophylactic use.

There is a significant correlation between isometric strength and isokinetic strength of a given muscle group (43). The results of the present study confirm that post-exercise CPK changes are closely associated to maximal isometric strength (44), and maximum isometric strength immediately after eccentric exercise is negatively associated with peak CPK activity (45). The present study identified a U-shaped CPK concentration/adductors isometric strength ratio curve. A significant decrease was observed for the POST1 measurements $24 \mathrm{~h}$ after the match:by $72 \mathrm{~h}$ after the match, the ratio had returned to basal values. Other studies evidenced a positive association between CPK peak activity and maximal isometric strength of lower extremity extensor muscles (46). The study of this biological behaviour can be used to assess the recovery of CPK level and adductors strength relative to each other during the competitive period, and to fine tune personalized training schemes during each microcycle.

Exercise modality can affect the appearance of CPK in blood serum. Following eccentric training, CPK serum levels can peak between $72 \mathrm{~h} \mathrm{(47)} \mathrm{and} 96 \mathrm{~h} \mathrm{(48)} \mathrm{to} 120 \mathrm{~h} \mathrm{(49).}$ Training status may affect this time response. Eccentric resistance training elicits a significantly different increase in CPK serum levels in resistance trained and untrained men: serum levels of CPK peak at $24 \mathrm{~h}$ in the resistance trained group, whilst they continue to raise and peak at $72 \mathrm{~h}$ in the untrained group (50).

We are aware that we report a snapshot within a competitive season. However, we point out that the results of our observations over three games at different stages of the competitive seasons were not significantly different, and therefore they likely reflect the actual response to the intense competition requirement of modern professional football. We are not sure that extending such observation to more games would allow to paint a different picture, and that it would impact on the practical implications delineated in the present study.

The question of the effect of the level of load on the increase in CPK could be the subject of future investigations in this field. We acknowledge that we did not study the pattern of motor activity and did not test physical qualities in the days of changes in physical performance and muscle strength: this could be incorporated in future 
experimentations. However, it should be kept in mind that we dealt with elite professional football players, for whom undertaking scientific research could be difficult and considered invasive of their performance capabilities.

We only studied the relationship between the serum level of CPK and muscle strength. Therefore, we could not ascertain how the level of CPK and a decrease in the strength of the adductors are related to the dynamics of various other parameters of physical performance, and how the level of daily physical activity can affect the indicators studied. This could be interpreted as a weakness of our work, and could be the subject of future endeavours.

The players taking part in the present study are all white Caucasian. This reflects the composition of the teams studied, and should prompt similar investigations in other ethnic groups, defining whether the findings of the present study are applicable to the whole population of elite professional football players.

\section{Conclusions}

Indirect muscle microtrauma after a professional soccer match significantly affects muscle strength parameters in professional soccer players during the competitive period. There is a strong negative association between serum CPK levels and adductor muscle strength-the faster the decrease in serum CPK levels, the faster the recovery of the isometric strength of the hip adductor muscle group. Serial serum CPK level measurement using finger prick sampling, combined with isometric dynamometry, is an easy and convenient method to check and evaluate the adaptation to exercise and recovery in professional football.

\section{Acknowledgments}

Funding: None.

\section{Footnote}

Reporting Checklist: The authors have completed the STROBE reporting checklist. Available at http://dx.doi. org/10.21037/atm-20-2923

Data Sharing Statement: Available at http://dx.doi. org/10.21037/atm-20-2923

Peer Review File: Available at http://dx.doi.org/10.21037/ atm-20-2923
Conflicts of Interest: All authors have completed the ICMJE uniform disclosure form (available at: http://dx.doi. org/10.21037/atm-20-2923). The authors declare no conflict of interest.

Ethical Statement: The authors are accountable for all aspects of the work in ensuring that questions related to the accuracy or integrity of any part of the work are appropriately investigated and resolved. All the procedures described in the present study were approved by our Local Ethics Committee (Sechenov Moscow State Medical University; Protocol No. 11-19, special meeting on 25.07.2019), and all participants signed a written informed consent. The study was conducted in accordance with the Declaration of Helsinki (as revised in 2013).

Open Access Statement: This is an Open Access article distributed in accordance with the Creative Commons Attribution-NonCommercial-NoDerivs 4.0 International License (CC BY-NC-ND 4.0), which permits the noncommercial replication and distribution of the article with the strict proviso that no changes or edits are made and the original work is properly cited (including links to both the formal publication through the relevant DOI and the license). See: https://creativecommons.org/licenses/by-nc-nd/4.0/.

\section{References}

1. Mougios V. Reference intervals for serum creatine kinase in athletes. Br J Sports Med 2007;41:674-8.

2. Thompson D, Williams C, Kingsley M, et al. Muscle Soreness and Damage Parameters after Prolonged Intermittent Shuttle-Running Following Acute Vitamin C Supplementation. Int J Sports Med 2001;22:68-75.

3. Morgan DL, Proske U. Popping sarcomere hypothesis explains stretch-induced muscle damage. Clin Exp Pharmacol Physiol 2004;31:541-5.

4. Khan FY. Rhabdomyolysis: a review of the literature. Neth J Med 2009;67:272-83.

5. Brancaccio P, Maffulli N, Politano L, et al. Persistent HyperCKemia in Athletes. Muscles Ligaments Tendons J 2011;1:31-5.

6. Brancaccio P, Maffulli N, Buonauro R, et al. Serum enzyme monitoring in sports medicine. Clin Sports Med 2008;27:1-18.

7. Brancaccio P, Maffulli N, Limongelli FM. Creatine kinase monitoring in sport medicine. Br Med Bull 2007;8182:209-30. 
8. Peake J, Nosaka K, Suzuki K. Characterization of inflammatory responses to eccentric exercise in humans. Exerc Immunol Rev 2005;11:64-85.

9. Baird MF, Graham SM, Baker JS, et al. Creatine-Kinaseand Exercise-Related Muscle Damage Implications for Muscle Performance and Recovery. J Nutr Metab 2012;2012:960363.

10. Magal M, Dumke, CL, Urbiztondo ZG, et al. Relationship between serum creatine kinase activity following exercise induced muscle damage and muscle fibre composition. J Sports Sci 2010;28:257-66.

11. Prelle A, Tancredi L, Sciacco M, et al. Retrospective study of a large population of patients with asymptomatic or minimally symptomatic raised serum creatine kinase levels. J Neurol 2002;249:305-11.

12. Koch AJ, Pereira R, Machado M. The creatine kinase response to resistance exercise. J Musculoskelet Neuronal Interact 2014;14:68-77.

13. Ispirlidis I, Fatouros IG, Jamurtas AZ, et al. Timecourse of Changes in Inflammatory and Performance Responses Following a Soccer Game. Clin J Sport Med 2008;18:423-31.

14. Coelho DB, Cabido CET, Ciminelli VAL, et al. Comparison of different ways of expressing creatine kinase concentration of soccer players during a competitive season. Motriz: Revista de EducacaoFísica 2016;22(3). doi: 10.1590/S1980-6574201600030006.

15. Khaitin VY, Matveev SV, Grishin MY. The level of serum creatine phosphokinase as a criterion of recovery in professional soccer players during the competitive period. Sports medicine: research and practice 2018;8:22-7.

16. Lazarim FL, Antunes-Neto JM, da Silva FO, et al. The upper values of plasma creatine kinase of professional soccer players during the Brazilian National Championship. J Sci Med Sport 2009;12:85-90.

17. Hader K, Rumpf MC, Hertzog M, et al. Monitoring the Athlete Match Response: Can External Load Variables Predict Post-match Acute and Residual Fatigue in Soccer? A Systematic Review with Meta-analysis. Sports Med Open 2019;5:48.

18. Silva JR, Rumpf MC, Hertzog M, et al. Acute and Residual Soccer Match-Related Fatigue: A Systematic Review and Meta-analysis. Sports Med 2018;48:539-83.

19. Thorborg K, Branci S, Nielsen MP, et al. Copenhagen five-second squeeze: a valid indicator of sports-related hip and groin function. Br J Sports Med 2017;51:594-9.

20. Owen A, Dunlop G, Rouissi M, et al. The relationship between lower-limb strength and match-related muscle damage in elite level professional European soccer players. J Sports Sci 2015;33:2100-5.

21. Werner J, Hagglund M, Walden $M$, et al. UEFA injury study: a prospective study of hip and groin injuries in professional football over seven consecutive seasons. Br J Sports Med 2009;43:1036-40.

22. Hölmich P. Long-standing groin pain in sportspeople falls into three primary patterns, a "clinical entity" approach: a prospective study of 207 patients. Br J Sports Med 2007;41:247-52; discussion 252.

23. Karlsson MK, Dahan R, Magnusson H, et al. Groin Pain and Soccer Players: Male Versus Female Occurrence. J Sports Med Phys Fitness 2014;54:487-93

24. Thorborg K, Rathleff MS, Petersen P, et al. Prevalence and Severity of Hip and Groin Pain in Sub-Elite Male Football: A Cross-Sectional Cohort Study of 695 Players. Scand J Med Sci Sports 2017;27:107-14.

25. Langhout R, Tak I, van Beijsterveldt AM, et al. Risk Factors for Groin Injury and Groin Symptoms in EliteLevel Soccer Players: A Cohort Study in the Dutch Professional Leagues. J Orthop Sports Phys Ther 2018;48:704-12.

26. Hørder M, Jorgensen PJ, Hafkenscheid JC, et al. Creatine Kinase Determination: A European Evaluation of the Creatine Kinase Determination in Serum, Plasma and Whole Blood with the Reflotron System. Eur J Clin Chem Clin Biochem 1991;29:691-6

27. Moreno-Pérez V, Travassos B, Calado A, et al. Adductor squeeze test and groin injuries in elite football players: A prospective study. Phys Ther Sport 2019;37:54-9.

28. Jensky-Squires NE, Dieli-Conwright CM, Rossuello A, et al. Validity and reliability of body composition analysers in children and adults. Br J Nutr 2008;100:859-65.

29. Nickerson BS, McLester CN, McLester JR, et al. Agreement Between 2 segmental Bioimpedance Devices, BOD POD, and DXA in Obese Adults. J Clin Densitom 2020;23:138-48.

30. Modric T, Versic S, Sekulic D, et al. Analysis of the Association Between Running Performance and Game Performance Indicators in Professional Soccer Players. Int J Environ Res Public Health 2019;16:4032.

31. Malliaropoulos N, Tsitas K, Porfiriadou A, et al. Blood phosphorus and magnesium levels in 130 elite track and field athletes. Asian J Sports Med 2013;4:49-53.

32. Fielding RA, Violan MA, Svetkey L, et al. Effects of prior exercise on eccentric exercise-induced neutrophilia and enzyme release. Med Sci Sports Exerc 2000;32:359-64.

33. Greene J, Louis J, Korostynska O, et al. State-of-the- 


\section{Page 10 of 10}

Art Methods for Skeletal Muscle Glycogen Analysis in Athletes-The Need for Novel Non-Invasive Techniques. Biosensors (Basel) 2017;7:11.

34. Aronson D, Wojtaszewski JF, Thorell A, et al. Extracellular-regulated protein kinase cascades are activated in response to injury in human skeletal muscle. Am J Physiol 1998;275:C555-61.

35. Saka T, Akova B, Yazici Z, et al. Difference in the magnitude of muscle damage between elbow flexors and Knee extensors eccentric exercises. J Sports Sci Med 2009;8:107-15.

36. Baker JS, Bailey DM, Hullin D, et al. Metabolic implications of resistive force selection for oxidative stress and markers of muscle damage during 30 s of highintensity exercise. Eur J Appl Physiol 2004:92:321-7.

37. Eckard TG, Padua DA, Dompier TP, et al. Epidemiology of hip flexor and hip adductor strains in National Collegiate Athletic Association athletes, 2009/20102014/2015. Am J Sports Med 2017;45:2713-22.

38. Hölmich P, Thorborg K, Dehlendorff C, et al. Incidence and clinical presentation of groin injuries in sub-elite male soccer. Br J Sports Med 2014;48:1245-50.

39. Stark T, Walker B, Phillips JK, et al. Hand-held dynamometry correlation with the gold standard isokinetic dynamometry: a systematic review. PM R 2011;3:472-9.

40. Lu TW, Hsu HC, Chang LY, et al. Enhancing the examiner's resisting force improves the reliability of manual muscle strength measurements: comparison of a new device with hand-held dynamometry. J Rehabil Med 2007;39:679-84.

41. Widler KS, Glatthorn JF, Bizzini M, et al. Assessment of hip abductor muscle strength: a validity and reliability study. J Bone Joint Surg Am 2009;91:2666-72.

42. Maffulli N, King JB, Helms P. Training in elite young

Cite this article as: Khaitin V, Bezuglov E, Lazarev A, Matveev S, Ivanova O, Maffulli N, Achkasov E. Markers of muscle damage and strength performance in professional football (soccer) players during the competitive period. Ann Transl Med 2021;9(2):113. doi: 10.21037/atm-20-2923
Khaitin et al. Markers of muscle damage in professional football

athletes (the Training of Athletes (TOYA) Study): injuries, flexibility and isometric strength. Br J Sports Med 1994;28:123-36.

43. Thorborg K, Branci S, Nielsen MP, et al. Eccentric and Isometric Hip Adduction Strength in Male Soccer Players with and Without Adductor-Related Groin Pain: An Assessor-Blinded Comparison. Orthop J Sports Med 2014;2:2325967114521778.

44. Kim J, Lee J. The relationship of creatine kinase variability with body composition and muscle damage markers following eccentric muscle contractions. J Exerc Nutrition Biochem 2015;19:123-9.

45. Nosaka K, Chapman D, Newton M, et al. Is isometric strength loss immediately after eccentric exercise related to changes in indirect markers of muscle damage? Appl Physiol Nutr Metab 2006;31:313-9.

46. Totsuka M, Nakaji S, Suzuki K, et al. Break point of serum creatine kinase release after endurance exercise. J Appl Physiol (1985) 2002;93:1280-6.

47. Paschalis V, Koutedakis Y, Jamurtas AZ, et al. Equal volumes of high and low intensity of eccercise in relation to muscle damage and performance. J Strength Cond Res 2005;19:184-8.

48. Chapman DW, Newton MJ, Zainuddin Z, et al. Work and peak torque during eccentric exercise do not predict changes in markers of muscle damage. Br J Sports Med 2008;42:585-91.

49. Sayers SP, Clarkson PM. Short-term immobilization after eccentric exercise. Part II: creatine kinase and myoglobin. Med Sci Sports Exerc 2003;35:762-8.

50. Hackney KJ, Engels HJ, Gretebeck RJ. Resting energy expenditure and delayed-onset muscle soreness after fullbody resistance training with an eccentric concentration. J Strength Cond Res 2008;22:1602-9. 